\title{
ELECTROPHORESIS
}

\section{Background conductivity independent counter flow pre- concentration method for capillary electrophoresis}

\begin{tabular}{|r|l|}
\hline Journal: & ELECTROPHORESIS \\
\hline Manuscript ID & elps.201700071.R1 \\
\hline Wiley - Manuscript type: & Short Communication \\
\hline Date Submitted by the Author: & $30-$ Mar-2017 \\
\hline Complete List of Authors: & $\begin{array}{l}\text { Koenka, Joel } \\
\text { Hauser, Peter; The University of Basel, Department of Chemistry }\end{array}$ \\
\hline Keywords: & capillary electrophoresis, pre-concentration, ion trapping \\
\hline \multicolumn{2}{|l}{} \\
\hline
\end{tabular}




\title{
Short Communication \\ Background conductivity independent counter flow pre-concentration method for capillary electrophoresis
}

\author{
Israel Joel Koenka ${ }^{1}$, Peter C. Hauser ${ }^{1, *}$ \\ ${ }^{1}$ Department of Chemistry, University of Basel, Spitalstrasse 51, 4056 Basel, Switzerland. \\ *Corresponding author. \\ E-mail address: Peter.Hauser@unibas.ch (P. C. Hauser) \\ Phone: ++416126710 03; Fax: ++41612671013
}

Keywords: capillary electrophoresis, pre-concentration, ion trapping.

Abbreviations: PAEKI, pressure assisted electrokinetic injection. 


\begin{abstract}
A pre-concentration method for anions is presented, which relies on a trap created by applying an electric field against a hydrodynamic flow of the sample. The trapping zone is created in front of a cation exchange membrane which allows the isolation of the electrode and thus prevents any interference by electrolysis products. Pre-concentration factors of up to 20 were demonstrated for nitrate and formate as model analyte ions and were linearly related to the sample volume passed through the trap. A discrimination between the ions was found possible by adjustment of the hydrodynamic flow velocity. The method was also found to be suitable for the preconcentration of an anion (nitrate at $100 \mu \mathrm{M}$ ) in presence of a second anion at a very high concentration (50 $\mathrm{mM}$ formate). The detection limits for the four anions chloride, nitrate, perchlorate and formate could be lowered from 4, 4.3, 4.2 and $7.2 \mu \mathrm{M}$ obtained without trapping respectively to $127,142,139$ and $451 \mathrm{nM}$ with trapping.
\end{abstract}


In comparison to chromatography, capillary electrophoresis has the advantages of relative simplicity and a low demand for consumables. This allows its implementation as low cost and portable systems (see for example $[1,2]$ ). A hindrance to wider acceptance are the relatively high limits of detection, which for optical detectors are due to the short available pathlengths. For contactless conductivity detection $\left(C^{4} D\right)$ these also seldom are lower than $1 \mu \mathrm{M}$, due to the presence of a background conductivity. For this reason there has been a strong interest in the development of analyte pre-concentration methods. An overview can be found in a recent review [3] and in a systematic guide [4] by Breadmore and coworkers. For capillary electrophoresis so-called stacking methods have been developed. These rely on the local creation of an electric field gradient in the sample zone, which leads to a faster movement of the ions causing them to pre-concentrate, i.e. to stack, at the zone boundary. However, with the possible exception of transient isotachophoresis, this is only possible for samples of low conductivity [4]. An alternative method, which is subjected less to this limitation, is counter-flow gradient electrofocusing. This makes use of a hydrodynamic flow in the direction opposite to the electrokinetic movement of the ions. By creating a gradient, or a step, in the electric field, a trapping zone is established as the ions experience forces driving them to the same area from either side. The topic has been reviewed by Shackman and Ross in 2007 [5] and the more recent developments have been summarized by Breadmore et al. [3] in 2015.

The field strength can be modified by changing the diameter of the channel, but this also alters the hydrodynamic flow velocity proportionally. Thus it is necessary to create a discontinuity by modifying the field with the help of an electrode which is in direct or indirect contact with the trapping zone. As described in the reviews, a variety of inchannel arrangements have been proposed. The challenge lies in the avoidance of 
interference through electrolysis products created at the electrodes (including the possible bubble creation due to oxygen or hydrogen evolution) and in achieving a robust arrangement on a scale that does not introduce bandbroadening. Good implementations are not easily achieved. Alternatively, as in Pressure Assisted Electrokinetic Injection (PAEKI) [6-8], the trapping is carried out at the inlet of the separation channel. However, this can be expected to be still affected by variations in the background conductivity (see e.g. the extensive discussions in $[9,10])$.

The device reported herein was designed with the intention of avoiding problems with electrolysis products and bubble formation, effects of varying background conductivities of samples and to obain a sharp sample plug inside the capillary for good resolution in the separation step. A sketch of the trapping cell, made from polymethyl methacrylate (PMMA), is given in Fig. 1A. It has the shape of an isosceles trapezoid and contains a flow through channel of $20 \mathrm{~mm}$ length with a diameter of $0.4 \mathrm{~mm}$ which has two $90^{\circ}$ turns. At these corners the channel is contacted by two cation exchange membranes (Nafion 117, Sigma-Aldrich, St. Louis, MO, USA). The chambers behind these membranes are filled with a buffer solution consisting of $0.5 \mathrm{M} 3-(\mathrm{N}-$ morpholino)propanesulfonic acid (MOPS) + 0.5 M sodium MOPS and contain electrodes made from stainless steel. A separation capillary (fused silica, $365 \mu \mathrm{m} \mathrm{OD,} 10 \mu \mathrm{m}$ ID, 50 cm length, Polymicro Technologies, Phoenix, AZ, USA) is mounted perpendicularly at the halfway point of the channel in the trapping device. As illustrated in Fig. 1B, fluid handling of the system is achieved with a pair of $20 \mu \mathrm{L}$ syringe pumps (SPS01-020-C360, LabSmith, Livermore, CA, USA), 3 two way valves (AV201-T116, LabSmith) and a 4 port selector valve (AV202-C360, LabSmith) which connects either ports A-C and B-D or A-D and B-C. The system is completed with a high voltage DC module capable of 
delivering up to $500 \mathrm{~V}$ (HMD-0.5R10-24-5-ER, Hivolt, Hamburg, Germany) and a second module with a maximum voltage of $30 \mathrm{kV}$ (Spellman CZE2000, Pulborough, UK). A purpose made $\mathrm{C}^{4} \mathrm{D}$ cell, similar to the one reported by Tanyanyiwa et al. [11], placed 20 $\mathrm{cm}$ from the inlet, was used for detection and its signal was captured with an e-corder (eDAQ, Denistone East, NSW, Australia) and processed with the Chart software package (eDAQ). All parts of the system were automatically operated using a purpose made graphical user interface software based on Instrumentino [12, 13].

Trapping of anions is achieved by pumping sample through the channel against a voltage applied through the two cation exchange membranes as illustrated in Fig. 1A. This leads to an accumulation of anions in front of the membrane on the left hand side if their electrokinetic velocity is higher than the hydrodynamic flow velocity. The use of the membranes prevents the creation of bubbles in the trapping channel. The current through the membranes is maintained by the transport of cations. It is thought that the charge of the anions pre-concentrated in front of the membrane is balanced by cations passed through the membrane. The fact that the trapping voltage is applied through the membranes directly across the sample solution also leads to the creation of consistent field strengths regardless of the conductivity of the sample.

The process is started by filling the channel with sample solution, followed by a period in which both the hydrodynamic flow and the electric field are applied. The flow through arrangement allows a flexible choice of sample volume. Subsequent to the trapping step the volume of the trapping zone is moved with the help of a syringe pump to the inlet of the separation capillary, where part of it is then injected hydrodynamically by pressurization, followed by flushing of the channel with the electrophoretic background 
electrolyte. The separation of the trapping zone from the capillary inlet assures a high integrity of the sample plug which enters the capillary. Analysis by zone electrophoresis is then carried out by application of the high voltage across two separate electrodes.

In Fig. 2 results obtained for formate and nitrate are reported, having mobilities of $56.6 \cdot 10^{-9}$ and $74.1 \cdot 10^{-9} \mathrm{~m}^{2} \cdot \mathrm{s}^{-1} \cdot \mathrm{V}^{-1}$ respectively (as calculated from the ionic conductivities tabulated in [14]). In Fig. 2A the enhancement factors for the two ions are plotted against different applied hydrodynamic flow rates while keeping the applied voltage constant. It can be seen that the enhancement factors are found to drop for flow rates higher than approximately 400 and $560 \mu \mathrm{m} \cdot \mathrm{s}^{-1}$ for formate and nitrate, respectively. The values match very well the expected limits in the flow rates for which trapping should be possible. These were calculated from the mobilities of the ions and the applied field strength of 75 $\mathrm{V} \cdot \mathrm{cm}^{-1}$ as 424 and $555 \mu \mathrm{m} \cdot \mathrm{s}^{-1}$ for the two ions. This clearly demonstrates that the implementation of the concept works. The fact that some enhancement is observed for both ions also for higher flow rates than these maxima must be due to imperfections caused by the laminarity of the hydrodynamic flow and distortion of the electric field in the angled arrangement of the trapping zone in front of the membrane. Sets of experiments were also carried out for field strengths of 35,150 and $250 \mathrm{~V} \cdot \mathrm{cm}^{-1}$ and the highest possible flow rates for maximal trapping were also found to correlate well with the expected values.

In Fig. 2B it is shown that the enhancement factor scales linearly with the volume of the sample passed through the cell. The experiment was carried out with a flow velocity of $318 \mu \mathrm{m} \cdot \mathrm{s}^{-1}$ and again an applied field strength of $75 \mathrm{~V} \cdot \mathrm{cm}^{-1}$. Under these conditions both, formate and nitrate are efficiently trapped. It is, however, also possible to selectively trap 
the ion with the higher mobility, namely nitrate. The mixture of formate and nitrate was passed through the cell at the higher flow velocity of $477 \mu \mathrm{m} \cdot \mathrm{s}^{-1}$, which according to prediction and the results of Fig. 2A is too high for efficient trapping of formate. As can be seen in Fig. 2C, nitrate is trapped as efficiently as for the lower flow rate, but as expected, formate is only trapped to a small extent. Why the enhancement factor for formate even drops slightly with increasing volume is not clear.

The effect of the composition of the solution was then tested. Pre-concentration experiments were carried out for solutions containing $100 \mu \mathrm{M}$ potassium nitrate and up to $50 \mathrm{mM}$ sodium formate. In all cases, nitrate was successfully pre-concentrated, despite the high background conductivity of the solutions due to the formate salt. An electropherogram for a pre-concentrated standard solution of $100 \mu \mathrm{M}$ potassium nitrate and $50 \mathrm{mM}$ sodium formate can be seen in Fig. 3A. An expanded view of the nitrate peak is shown in the inset together with the peak for nitrate for the solution not subjected to the trapping experiment demonstrating the increase in concentration achieved for the high ionic background.

Finally, it was examined if the system can be employed for lowering the LODs for CE$\mathrm{C}^{4} \mathrm{D}$ by examining the behaviour for the four anions chloride, nitrate, perchlorate and formate. Without carrying out the trapping step LODs of 4, 4.3, 4.2 and 7.2 $\mu \mathrm{M}$ were determined for the 4 anions respectively under the $C E-C^{4} \mathrm{D}$ conditions employed. Trapping from a volume of $150 \mu \mathrm{L}$ with an applied field strength of $150 \mathrm{~V} \cdot \mathrm{cm}^{-1}$ and a flow velocity of $663 \mu \mathrm{m} \cdot \mathrm{s}^{-1}$ resulted in LODs of $127,142,139$ and $451 \mathrm{nM}$. The separation of the ion mixture following pre-concentration from $500 \mathrm{nM}$, which is well below the LOD without pre-concentration, is shown in Fig. 3B. Note, that the flow 
velocity of $663 \mu \mathrm{m} \cdot \mathrm{s}^{-1}$ corresponds to a volumetric flow rate of $5 \mu \mathrm{L} \cdot \mathrm{min}^{-1}$ for the set-up employed which means that the trapping experiment for the $150 \mu \mathrm{L}$ of standard solution had a duration of $30 \mathrm{~min}$.

In conclusion, a fully automated pre-concentration system based on balancing hydrodynamic and electrokinetic flows was built and integrated into a miniaturized capillary electrophoresis instrument. In contrast to the electrokinetic stacking methods employed in capillary electrophoresis, the method has the advantage of working even for high conductivity samples and a discrimination between slow and fast ions could be achieved by adjustment of the flow rate. The results are preliminary and there is room for improvement of the pre-concentration factors and the trapping times. Although only anions were tested thus far, the same principle should be applicable for cations as well, using anion-exchange membranes and reverse voltages.

\section{Acknowledgements}

The authors are grateful for financial support by the Swiss National Science Foundation through grants 200020-137676 and 200020-149068. 


\section{References}

[1] Gregus, M., Foret, F., Kubáñ, P., J. Chromatogr. A 2016, 1427, 177-185.

[2] Koenka, I. J., Küng, N., Kubán̆, P., Chwalek, T., Furrer, G., Wehrli, B., Müller, B., Hauser, P. C., Electrophoresis 2016, 37, 2368-2375.

[3] Breadmore, M. C., Tubaon, R. M., Shallan, A. I., Phung, S. C., Keyon, A. S. A., Gstoettenmayr, D., Prapatpong, P., Alhusban, A. A., Ranjbar, L., See, H. H., Dawod, M., Quirino, J. P., Electrophoresis 2015, 36, 36-61.

[4] Breadmore, M. C., Sänger-Van De Griend, C. E., LCGC N. Am. 2014, 32, 174-186.

[5] Shackman, J. G., Ross, D., Electrophoresis 2007, 28, 556-571.

[6] Feng, Y.-L., Zhu, J., Anal. Chem. 2006, 78, 6608-6613.

[7] Xu, Z., Li, A., Wang, Y., Chen, Z., Hirokawa, T., J. Chromatogr. A 2014, 1355, 284-290.

[8] D'Ulivo, L., Feng, H. T., Electrophoresis 2015, 36, 1024-1027.

[9] Hirokawa, T., Koshimidzu, E., Xu, Z., Electrophoresis 2008, 29, 3786-3793.

[10] Gstoettenmayr, D., Quirino, J., Ivory, C. F., Breadmore, M. C., J. Chromatogr. A $2015,1408,236-242$.

[11] Tanyanyiwa, J., Galliker, B., Schwarz, M. A., Hauser, P. C., Analyst 2002, 127, $214-$ 218.

[12] Koenka, I. J., Sáiz, J., Hauser, P. C., Comput. Phys. Commun. 2014, 185, 27242729.

[13] Koenka, I. J., Sáiz, J., Hauser, P. C., Chimia 2015, 69, 172-175.

[14] Lide, D. R. E., CRC Handbook of Chemistry and Physics, CRC Press, Boca Raton 1995. 


\section{Figure Captions:}

Fig. 1 A) Pre-concentration cell. B) Microfluidic system. HV = high voltage, $\mathrm{BGE}=$ background electrolyte.

Fig. 2 A) Enhancement factors for nitrate and formate as a function of the applied flow velocity for an applied field strength of $75 \mathrm{~V} \cdot \mathrm{cm}^{-1}$ and a volume of $15 \mu \mathrm{L}$. Standard solution: $50 \mu \mathrm{M}$ potassium nitrate, $100 \mu \mathrm{M}$ sodium formate. The two vertical lines represent the theoretical maximal flow rates at which trapping is possible. Injection: $20 \mathrm{~s}$ at $100 \mathrm{kPa}$. Separation voltage: $25 \mathrm{kV}$. Background electrolyte: $30 \mathrm{mM}$ histidine, $30 \mathrm{mM}$ acetic acid.

B) Enhancement factors for nitrate and formate as a function of the volume of sample passed through the trapping cell for an applied flow velocity of $318 \mu \mathrm{m} \cdot \mathrm{s}^{-}$ ${ }^{1}$ and an applied field strength of $75 \mathrm{~V} \cdot \mathrm{cm}^{-1}$. Other conditions as for Fig. 2A. C) Enhancement factors for nitrate and formate as a function of the volume of sample passed through the trapping cell for an applied flow velocity of $477 \mu \mathrm{m} \cdot \mathrm{s}^{-}$ ${ }^{1}$ and an applied field strength of $75 \mathrm{~V} \cdot \mathrm{cm}^{-1}$. Other conditions as for Fig. 2A.

Fig. 3 A) Separation of a pre-concentrated high conductivity standard solution. Hydrodynamic flow velocity: $265 \mu \mathrm{m} \cdot \mathrm{s}^{-1}$. Field strength: $35 \mathrm{~V} \cdot \mathrm{cm}^{-1}$. Standard solution: $15 \mu \mathrm{L}$ of $100 \mu \mathrm{M}$ potassium nitrate, $50 \mathrm{mM}$ sodium formate. BGE: 300 $\mathrm{mM}$ histidine, $300 \mathrm{mM}$ acetic acid. Other conditions as for Fig. 2A. A magnification of the pre-concentrated nitrate peak (full line) is overlaid on the non-concentrated nitrate peak (dotted line) in the inset. 
1

2

3

4

5

6

7

8

9

10

11

12

13

14

15

16

17

18

19

20

21

22

23

24

25

26

27

28

29

30

31

32

33

34

35

36

37

38

39

40

41

42

43

44

45

46

47

48

49

50

51

52

53

54

55

56

57

58

59

60

B) Separation of $500 \mathrm{nM}$ chloride, nitrate, perchlorate and formate following preconcentration. Hydrodynamic flow velocity: $663 \mu \mathrm{m} \cdot \mathrm{s}^{-1}$. Field strength: 150 $\mathrm{V} \cdot \mathrm{cm}^{-1}$. Volume of standard solution: $150 \mu \mathrm{L}$. Other conditions as for Fig. 2A. 


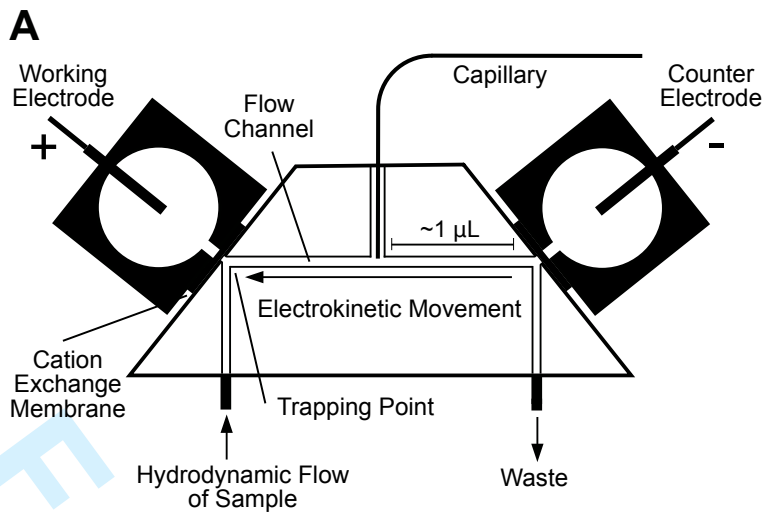

B

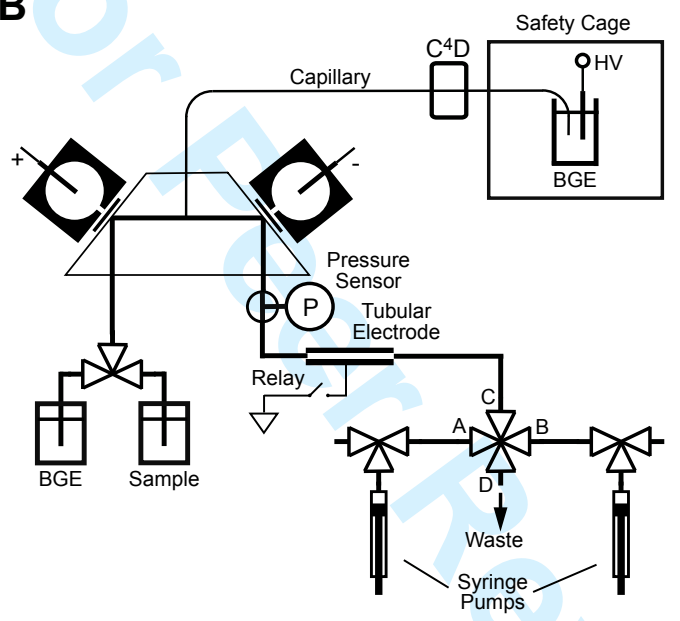

Figure 1 

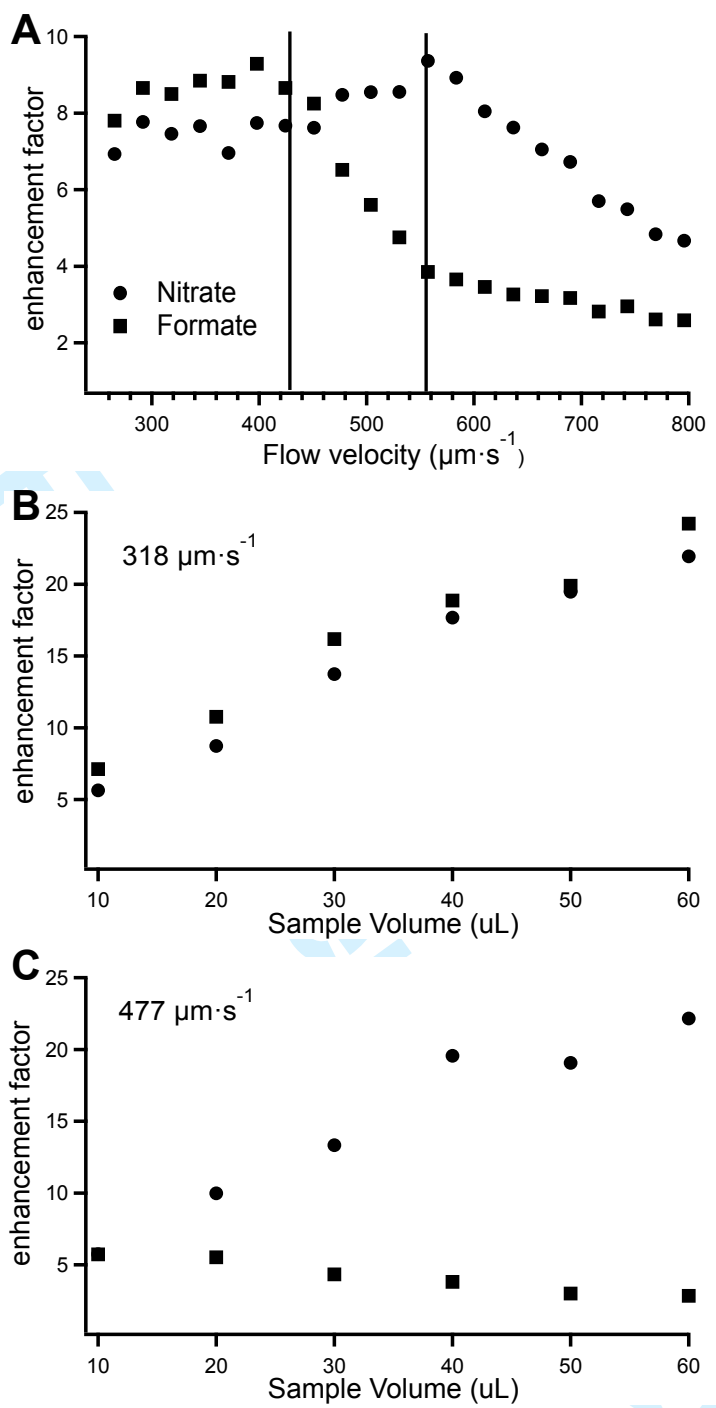

Figure 2 

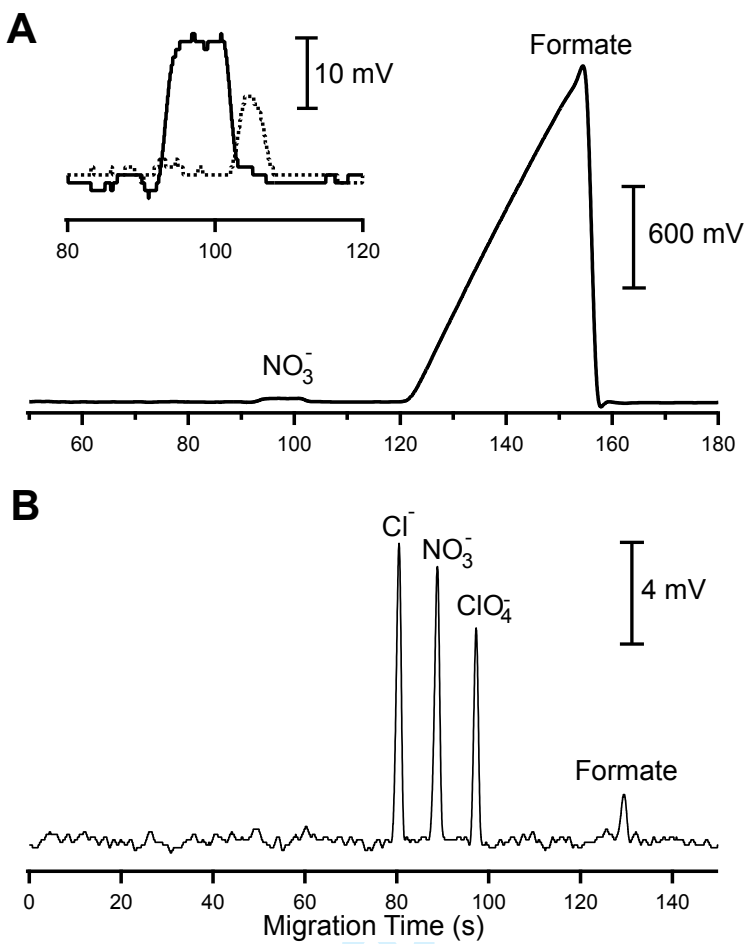

Figure 3 